\title{
Influence of the incorporation of metals on the optical properties of MCM-41
}

\author{
Ya-Ping Hsieh ${ }^{\mathrm{a}}$, Ji-Wei Chen ${ }^{\mathrm{a}}$, Chi-Te Liang ${ }^{\mathrm{a}, *}$, Yang-Fang Chen ${ }^{\mathrm{a}, *}$, \\ Ai-Qin Wang ${ }^{\mathrm{b}}$, Chung-Yuan Mou ${ }^{\mathrm{b}}$ \\ ${ }^{a}$ Department of Physics, National Taiwan University, Taipei 106, Taiwan \\ ${ }^{\mathrm{b}}$ Department of Chemistry, National Taiwan University, Taipei 106, Taiwan
}

Received 18 January 2007; received in revised form 26 June 2007; accepted 19 October 2007

Available online 4 November 2007

\begin{abstract}
We studied the optical properties of mesoporous aluminosilica incorporated with metal nanoparticles, which can be used to efficiently enhance catalytic activity for CO oxidation. Analysis of the PL spectra indicated that the incorporation of Al greatly enhanced the generation of oxygen related defects. When Au nanoparticles were deposited onto Al-MCM-41, both the PL and PLE spectra suggested that the metal nanoparticles were strongly attracted by the electrostatic force induced by the charged oxygen defects. Electron spin resonance measurement provided further evidence, registering a spike in the $\mathrm{O}_{2}^{-}$intensity following incorporation of the metal particles, as the strong interaction between the $\mathrm{F}+$ center and the metal particles induced electron transfer to the trapped $\mathrm{O}_{2}$ molecule. These discoveries shed further light on the perplexing mechanism by which the $\mathrm{Si} / \mathrm{Al}$ ratio and metal particles can give rise to dramatic enhancement of the catalytic activity for $\mathrm{CO}$ oxidation.
\end{abstract}

(C) 2007 Elsevier B.V. All rights reserved.

PACS: 78.66.Sq; 78.67.Hc

Keywords: Gold nanoparticles; Photoluminescence; Catalytic activity; Oxidation; Al-MCM; Defect; EPR spetroscopy; Photoluminescence excitation; Nucleation

\section{Introduction}

Mesoscale materials are an important class of functional objects whose dimensions span from individual molecules to macroscopic structures. In particular, mesoporous materials are ideal hosts for constructing organic and inorganic nanostructures. These new functional materials have potential applications in catalyzing macromolecules [1-3] and in optoelectronic devices, such as vertical-cavity surface-emitting lasers (VCSELs), photodiodes, and lightemitting diodes in long wavelength optical-fiber communications [4-6]. MCM-41 [7] is one of the most versatile ordered mesoporous materials, and has been used as an adsorbent and for catalysis support.

\footnotetext{
${ }^{*}$ Corresponding authors. Tel.: +886233665125 .

E-mail addresses: ctliang@phys.ntu.edu.tw (C.-T. Liang), yfchen@phys.ntu.edu.tw (Y.-F. Chen).
}

The discovery of Haruta and co-workers concerning the catalysis of gold nanoparticles in a class of oxygen-transfer reactions brought worldwide attention [8]. The catalytic activity has been found to be sensitive to the nature of the support used (such as $\mathrm{TiO}_{2}, \mathrm{Fe}_{2} \mathrm{O}_{3}$ and MCM-41); but the mechanism through which the metal nanoparticles adhere to the support is at yet not well understood $[9,10]$. It was also found that the incorporation of aluminum into the MCM-41 framework will dramatically enhance its catalytic properties because of the increase in the acidic property as well as the number of defects $[1-3,11]$. However, the origin for the enhancement is also not clear.

Measurements of the optical properties of ordered mesoporous materials such as MCM-41 can provide important information on the electronic energy states, which will be helpful for analyzing the defect structures. In addition, a better understanding of the optical properties would facilitate the application of MCM-41 in optical 
devices. Photoluminescence (PL) has been previously used in optical studies of silicious MCM-41 [12-19], and been shown to provide a wealth of insights for better understanding of the material. For example, the red PL in MCM-41 has been attributed to the non-bridging oxygen hole centers (NBOHCs) [16,19]. On the other hand, the blue-green PL has been ascribed to the $\mathrm{Si}-\mathrm{OH}$ surface complexes [17,18] and two-fold-coordinated silicon centers $\left(\mathrm{Si}_{2}^{0}\right)$ [13-15]. However, only a very limited number of papers have been devoted to the study of aluminosilicate MCM-41 (denoted as Al-MCM-41) [20-23]. Mary et al. [21] performed the first PL study on Al-MCM-41 and found that the emission of aluminosilicate MCM-41 appeared to be correlated with the presence of the aluminum framework. Also, Chang et al. [20] have discovered that there exists triplet to singlet transitions associated with $\mathrm{Si}-\mathrm{OH}$ bonding in tubules-within-tubule structure Al-MCM-41, and that these transitions are not related to the presence of the aluminum atoms.

In addition, Chang et al. also found that the luminescence can persist for a very long period of time. In this paper, we report a detailed study of the UV-blue photoluminescent properties of $\mathrm{Al}-\mathrm{MCM}-41$ as well as $\mathrm{Au}$ nanoparticles deposited on Al-MCM-41 support (denoted as Au@Al-MCM-41). Strong PL enhancement was found after aluminum was incorporated into MCM-41. The emissions due to charged oxygen vacancies and excess defects have been identified, indicating that the incorporation of Al can greatly increase oxygen related defects. When $\mathrm{Au}$ nanoparticles were deposited onto Al-MCM-41, the intensity of the PL decays dramatically, especially for those peaks originating from the charged oxygen vacancies. With the help of electron paramagnetic resonance (EPR) and PLE, we infer that the $\mathrm{Au}$ nanoparticles are strongly attracted by electrostatic forces arising from the charged oxygen vacancy defects, leading to changes in the energy states of the defects and a reduction in the luminescent intensity. This result implies that there exists a strong interaction between the oxygen vacancies and metal nanoparticles and therefore the defects generated by $\mathrm{Al}$ can be used to stabilize the metal nanoparticles and prevent them from sintering during the high temperature treatment. Besides, the PL results strongly support our EPR measurement, in which the $\mathrm{O}_{2}^{-}$intensity increases sharply after the incorporation of metal nanoparticles. Our results once again underline the usefulness of PL studies for the understanding of the physical as well as chemical properties of mesoporous materials.

\section{Experimental}

To prepare A1-MCM-41, a proper amount of sodium aluminate $\left(54 \% \quad \mathrm{Al}_{2} \mathrm{O}_{3}\right.$, Riedel-deHaen) was added to sodium silicate solution ( $27 \%$ silica, Aldrich), and the mixture was adjusted to a $\mathrm{pH}$ value of 9 while stirring at $40{ }^{\circ} \mathrm{C}$. Then, the mixture was poured into the surfactant CTAB solution to form a gel. The gel composition was
(1.0) $\mathrm{SiO}_{2}:(00.071) \mathrm{NaAlO}_{2}:(0.18) C 16 T M A B:(493) \mathrm{H}_{2} \mathrm{O}$, to give a $\mathrm{Si} / \mathrm{Al}$ ratio of $14,24,74$, and $\infty$. The gel mixture was heated statically at $100^{\circ} \mathrm{C}$ for $6 \mathrm{~h}$ in an autoclave. The solid products were isolated by suction filtration, washed with deionized water, then calcinated at $560^{\circ} \mathrm{C}$ in air for $6 \mathrm{~h}$ to remove the organic templates [23].

$\mathrm{Au} @ \mathrm{Al}-\mathrm{MCM}-41$ was synthesized according to the procedures described earlier [24]. The total Au loading was $8 \mathrm{wt} \%$, and the $\mathrm{Si} / \mathrm{Al}$ molar ratio was 24 . The transmission electron microscope (TEM) image of $\mathrm{Au} @ \mathrm{Al}-\mathrm{MCM}-41$ is shown in Fig. 1. The TEM image reveals that there are several (diameter $<5 \mathrm{~nm}$ ) $\mathrm{Au}$ nanoparticles on Al-MCM-41, and the mesoporous silica particles are very disordered, having a domain size of around $50 \mathrm{~nm}$ with a large fraction of textural porosity. It can also be seen that the Au particles are mostly located in the pores. Even if there may exist a substantial fraction of amorphous phase, it will not affect our result shown here, because our main concern is the effects of Au particles incorporation on the defect properties. The effects of the $\mathrm{Au}-\mathrm{Ag}$ size and $\mathrm{Au}$ alloys on the characteristics of catalysis and a detailed structural analysis of the samples have been published elsewhere [23].

Room temperature PL and PLE data were recorded using a SPEX Flurolog-2 instrument equipped with a double emission monochromator and a R928 photomultiplier tube. Excitation was provided by a $450 \mathrm{~W}$ Xe lamp whose output was focused into a $0.22 \mathrm{~m}$ monochromator to provide wavelength selection. EPR spectra were recorded at $-189^{\circ} \mathrm{C}$ with a Bruker EMX spectrometer working in the X-band $(9.53 \mathrm{GHz})$.

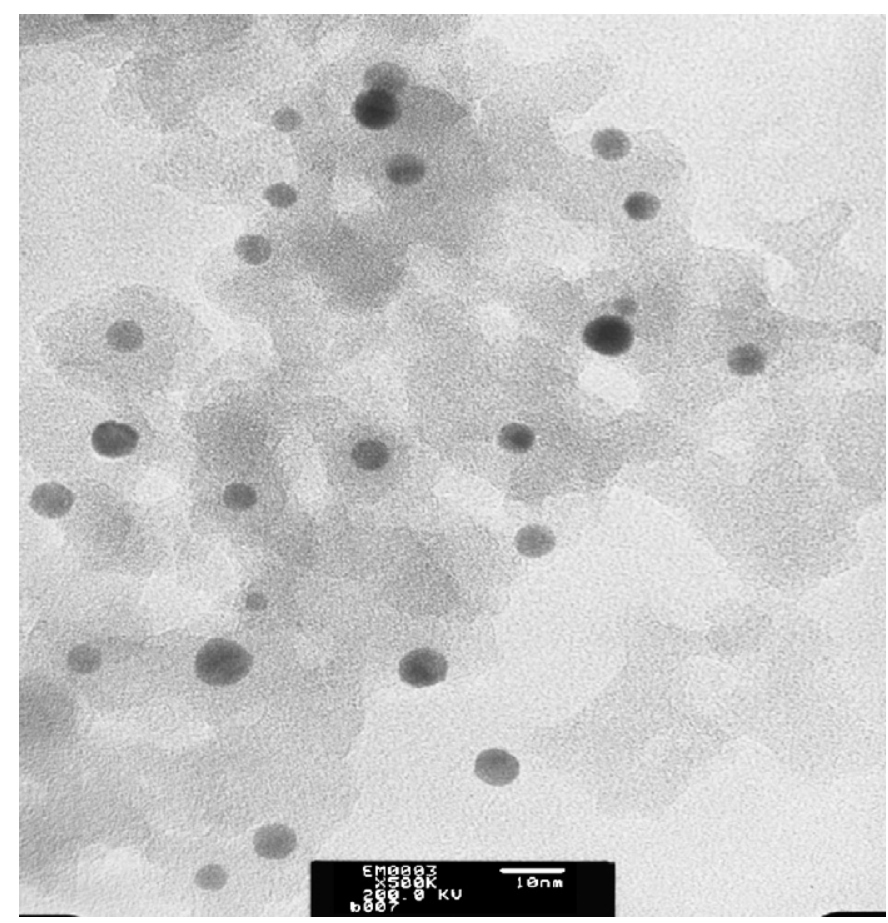

Fig. 1. Transmission electron microscope (TEM) image of $\mathrm{Au} @ \mathrm{Al}-\mathrm{MCM}-41$ with the scale bar of $10 \mathrm{~nm}$. 
$\mathrm{Au}$ nanoparticles ranging from $1 \times 10^{14}$ to $1 \times$ $10^{21}$ atom $/ \mathrm{cm}^{2}$ in concentration. (b) Normalized $R(\lambda)$ for the same samples as Fig. 3(b). Curves have been successively offset for clarity.

\section{Results and discussion}

A number of different excitation wavelengths were used to measure the PL spectra of Al-MCM-41, as shown in Fig. 2(a). From top to bottom, the excitation wavelength used was 306, 284, and $270 \mathrm{~nm}$, respectively. One can see that there are four peaks, at around 355, 391, 412, and $435 \mathrm{~nm}$, respectively. For the excitation wavelength at $270 \mathrm{~nm}$ (curve (i)), there existed a PL shoulder at around $355 \mathrm{~nm}$. For the excitation wavelength of $284 \mathrm{~nm}$, (curve (ii)), the peak was positioned at $412 \mathrm{~nm}$. For the case of the $306 \mathrm{~nm}$ excitation wavelength, one obtained a maximum at $391 \mathrm{~nm}$ (curve (iii)). For all of the above-mentioned curves, there seemed to be a shoulder at around $435 \mathrm{~nm}$. Relative

a

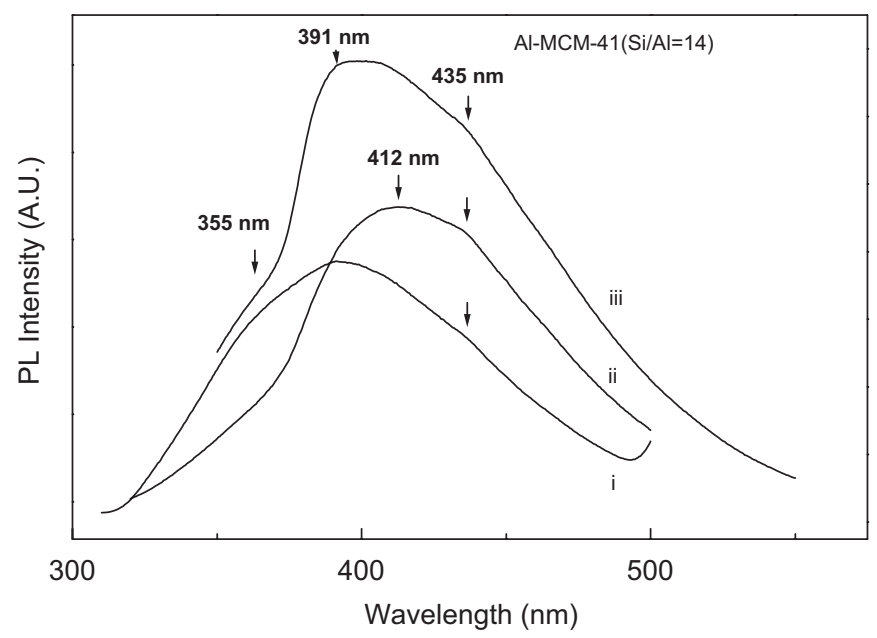

b

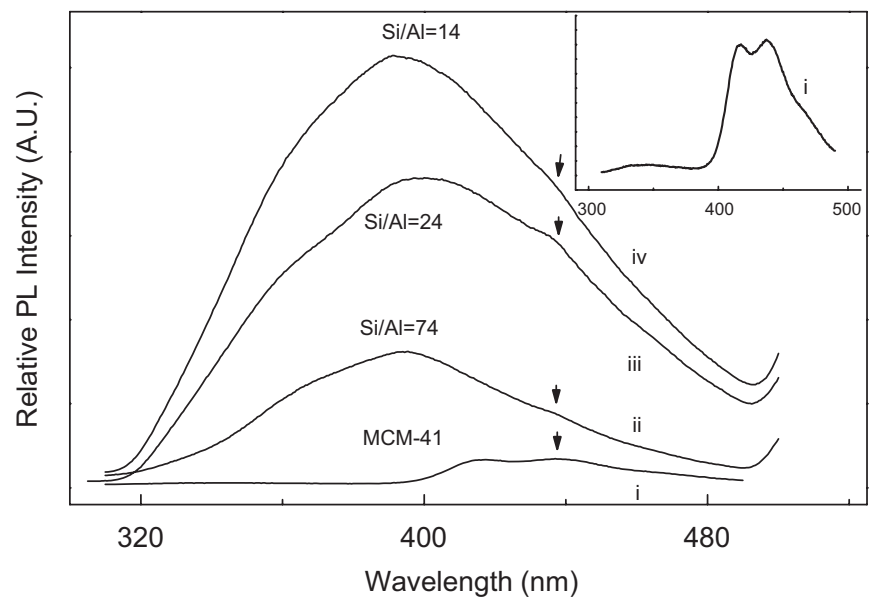

Fig. 2. (a) The photoluminescence spectra of Al-MCM-41 obtained with excitation wavelength of (i) $270 \mathrm{~nm}$, (ii) $284 \mathrm{~nm}$, and (iii) $306 \mathrm{~nm}$. (b) Photoluminescence spectra of $\mathrm{Al}-\mathrm{Si}-\mathrm{MCM}-41$ with different $\mathrm{Si} / \mathrm{Al}$ ratios measured under excitation wavelength of $270 \mathrm{~nm}$. photoluminescent intensities of Al-MCM-41 with different $\mathrm{Si} / \mathrm{Al}$ molar ratios measured under the photoexcitation of $270 \mathrm{~nm}$ were shown in Fig. 2(b). From top to bottom, the ratio of $\mathrm{Si} / \mathrm{Al}$ was $14,24,74$, and $\infty$ (i.e. silicious MCM-41), respectively. Interestingly, after incorporating aluminum atoms into the framework of MCM-41 and replacing the silicon atom, one obtained a two order enhancement in the PL intensity. The origin of this striking behavior will be discussed below.

Firstly, it is helpful to identify the peaks that come from silicious MCM-41 alone and those that come from Al-MCM-41 by comparing their spectra. The silicious MCM-41 also has a smaller peak at around $350 \mathrm{~nm}$, as shown magnified in the inset of Fig. 2(b), and the peak position does not appear to shift regardless of the $\mathrm{Si} / \mathrm{Al}$ ratio. While surveying the PLE spectra with the monochromator fixed at $350 \mathrm{~nm}$, as shown in Fig. 3(a), both the silicious MCM-41 and Al-MCM-41 have a similar PLE peak at around $270 \mathrm{~nm}$. The same PL spectrum had been observed in a previous study of MCM-41, but was marked as unknown [12]. Indeed, this particular PL peak at about $350 \mathrm{~nm}$ had been found in $\mathrm{SiO}_{2}$ powder as well as oxidized porous silicon and it was attributed to oxygen excess defects such as $\mathrm{Si}-\mathrm{O}-\mathrm{O}-\mathrm{Si}[25,26]$. Incidentally, all of the PLE spectra have a similar peak at around $270 \mathrm{~nm}$ as shown here [25]. We therefore propose that the $\mathrm{Si}-\mathrm{O}-\mathrm{O}-\mathrm{Si}$ oxygen excess defects are responsible for the $350 \mathrm{~nm}$ emission observed here and in previous reports. A slight shift can be interpreted as being due to the different values of $x$ in $\mathrm{SiO}_{x}$, which in turn alters the nature of the energy states of the transition [27].

In Fig. 2(b), a shoulder at $435 \mathrm{~nm}$ is present in all of the PL spectra for Al-MCM-41, the same as the peak found in silicious MCM-41. It was an open question whether the blue light emission of MCM-41 arises from the $\mathrm{Si}-\mathrm{OH}$ $[17,18]$ or the electronic transition of ${ }^{3} \mathrm{~B}_{1} \rightarrow{ }^{1} \mathrm{~A}_{1}$ in a twofold-coordinated silicon $\left(\mathrm{Si}_{2}^{0}\right)[13,15]$; which was regarded as a bent quasimolecule with a ${ }^{1} \mathrm{~A}_{1}$ round state, a firstexcited ${ }^{1} B_{1}$ singlet state, and a ${ }^{3} B_{1}$ triplet state [28]. But with the monochromator fixed at $435 \mathrm{~nm}$, as shown in Fig. 3(b), a PLE peak at $365 \mathrm{~nm}$ was observed in both MCM-41 and Al-MCM-41. Meanwhile, the energy of the $365 \mathrm{~nm}$ peak approaches the calculated values of $3.45 \mathrm{eV}$ for the direct singlet-to-triplet excitation transition in the two-coordinated $\mathrm{Si}$ center based on the oxygen vacancy and cluster model $[29,30]$. Therefore, one can conclude that the blue PL peak of Al-MCM-41 in our sample at around $435 \mathrm{~nm}$ is due to the defects. Comparing the PLE spectra of Al-MCM-41 to MCM-41, one can also find that the PLE spectrum of Al-MCM-41 has two additional peaks at 284 and $306 \mathrm{~nm}$, which do not appear in the spectra of MCM-41. Therefore they must be a result of the incorporation of aluminum, an observation which will prove very useful for the following discussion. In Fig. 4, for the excitation wavelength of $270 \mathrm{~nm}$, the PL spectra show a maximum intensity at $391 \mathrm{~nm}$ (see curve (i)). After annealing at $450^{\circ} \mathrm{C}$ in $\mathrm{N}_{2}$ gas, the PL peaks at around 391 
a

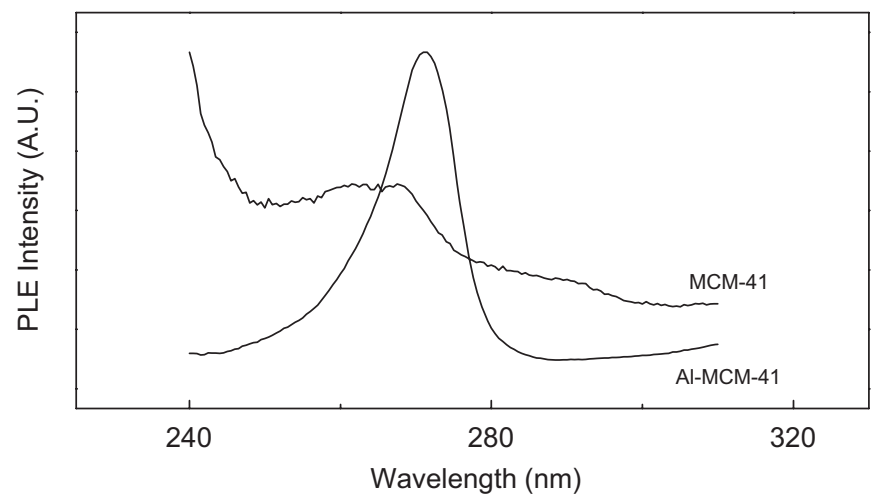

b

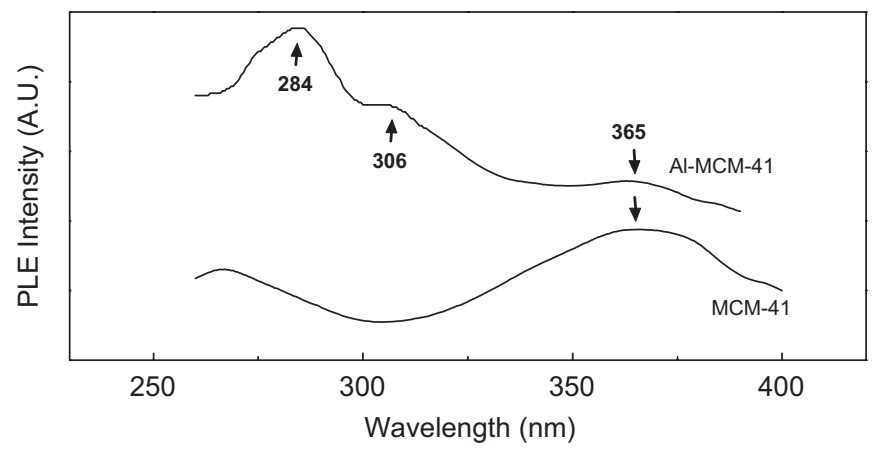

C

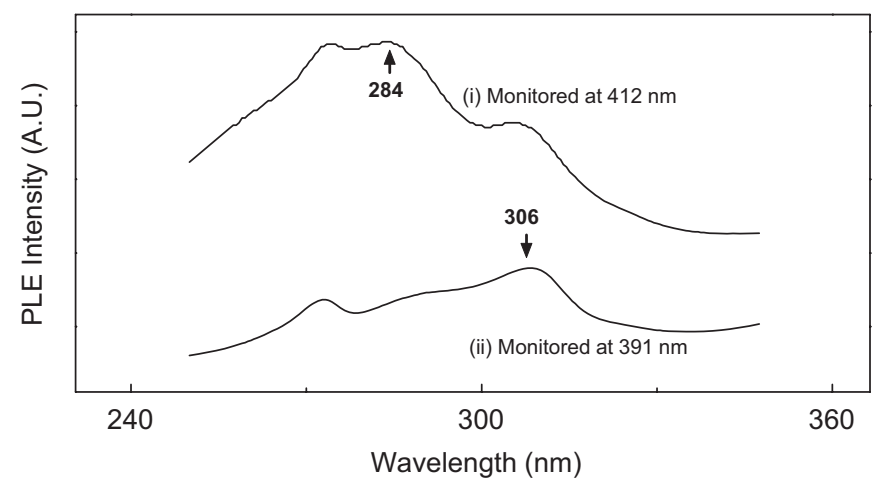

Fig. 3. (a) Photoluminescence excitation spectra of MCM-41 and Al-MCM-41 with the monochromator fixed at $350 \mathrm{~nm}$. (b) Photoluminescence excitation spectra of MCM-41 and Al-MCM-41 with the monochromator fixed at $435 \mathrm{~nm}$. (c) Photoluminescence excitation spectra of Al-MCM-41 with the monochromator fixed at (i) $412 \mathrm{~nm}$ and (ii) $391 \mathrm{~nm}$.

and $350 \mathrm{~nm}$ of the Al-MCM-41 decay drastically, while the peak at $435 \mathrm{~nm}$ is insensitive to the annealing as can be seen from the curve (ii). We can thus infer that the PL peak of Al-MCM-41 at $391 \mathrm{~nm}$ is probably also due to the oxygen excess defects. After annealing, the excess oxygen gets evaporated and the PL intensity decreases accordingly. An additional piece of evidence to support the role played by the oxygen excess defects will be provided later. The PLE spectra with the monochromator fixed at $391 \mathrm{~nm}$ is shown in Fig. 3(c), and one can see that the $306 \mathrm{~nm}$ excitation has a significant contribution to the $391 \mathrm{~nm}$ emission. This behavior implies that the oxygen excess defects are related to the aluminum atoms as discussed above. Intriguingly,

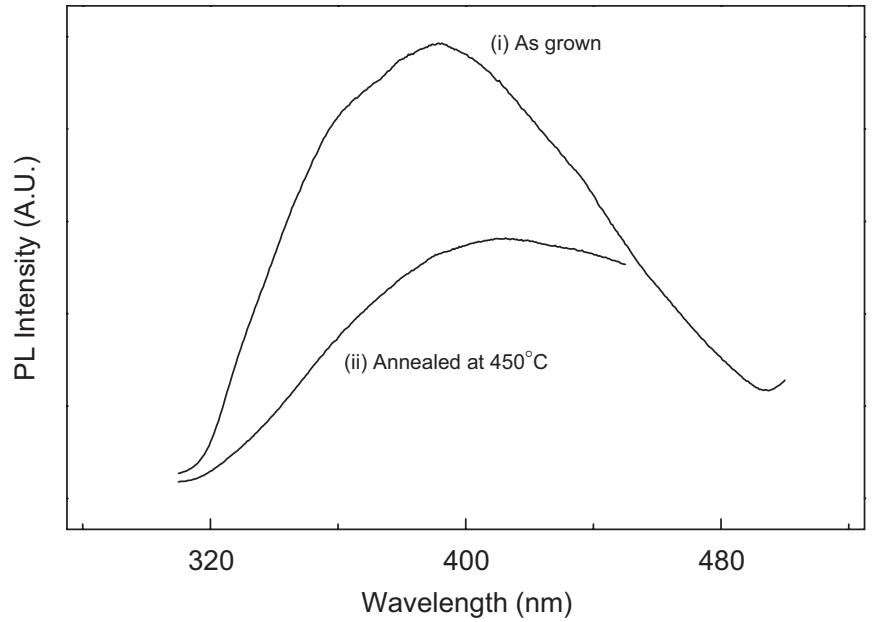

Fig. 4. Photoluminescence spectra of Al-MCM-41 before and after annealing at $450^{\circ} \mathrm{C}$ in $\mathrm{N}_{2}$.
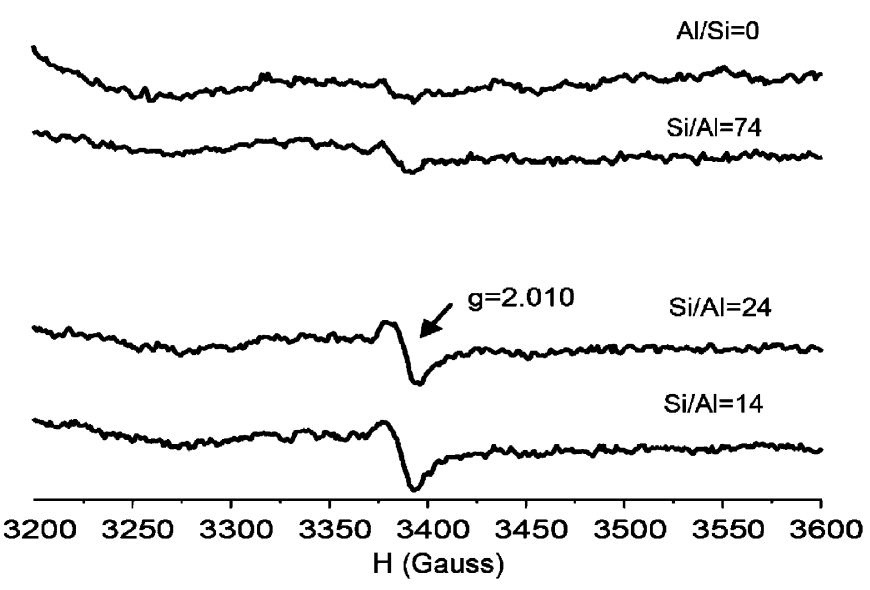

Fig. 5. Electron paramagnetic resonance (EPR) spectra of Al-MCM-41 with different $\mathrm{Si} / \mathrm{Al}$ ratios.

the peak positions of the PLE spectra with the monochromator fixed at these two peaks are similar. This behavior may be attributed to the fact that when electrons were excited to the higher energy states, they would ultimately relax back to both of the states responsible for the transitions of 391 and $412 \mathrm{~nm}$. As a consequence, the PLE spectra as shown in Fig. 3(c) were obtained.

In Fig. 2(a), for the excitation wavelength of $284 \mathrm{~nm}$ (see curve (ii)), the PL spectrum has a maximum intensity at $412 \mathrm{~nm}$. The PLE spectrum with the monochromator fixed at $412 \mathrm{~nm}$ is shown in Fig. 3. One can see an obvious correlation between the $284 \mathrm{~nm}$ excitation and the $412 \mathrm{~nm}$ emission. In recent years, it has been widely speculated that the $\mathrm{F}+$ center (oxygen vacancy trapping an electron) can result in strong PL spectrum centered around $412 \mathrm{~nm}$ in alumina membranes, and Si-based anodic porous alumina films [31-33]. Our EPR measurements of A1-MCM-41 provide further evidence to support the claim that the $\mathrm{F}+$ center is indeed responsible for the $412 \mathrm{~nm}$ emission. EPR has proved to be a very sensitive technique for the detection of charged defects in a solid [34]. In Fig. 5, a clear EPR 
signal with a $g$ factor of 2.010 appears in the EPR spectra. Claus et al. [35] have also observed a similar EPR signal with $g=2.010$ in Al-MCM-41, which was ascribed to the $\mathrm{O}_{2}^{-}$radicals stabilized on the $\mathrm{Al}$ cations. Our EPR signal indicates that the higher the $\mathrm{Al}$ contents of the support, the stronger the EPR signal. This behavior can be easily understood as follows. The incorporation of aluminum will lead to the generation of charged oxygen vacancy defects $(\mathrm{F}+$ center $)$ as well as oxygen excess defect. When the fraction of incorporated $\mathrm{Al}$ is increased, one can see the enhanced peak at $391 \mathrm{~nm}$, as displayed in Fig. 2(b). It is also evident that the more charged defects $(\mathrm{F}+$ center and

a

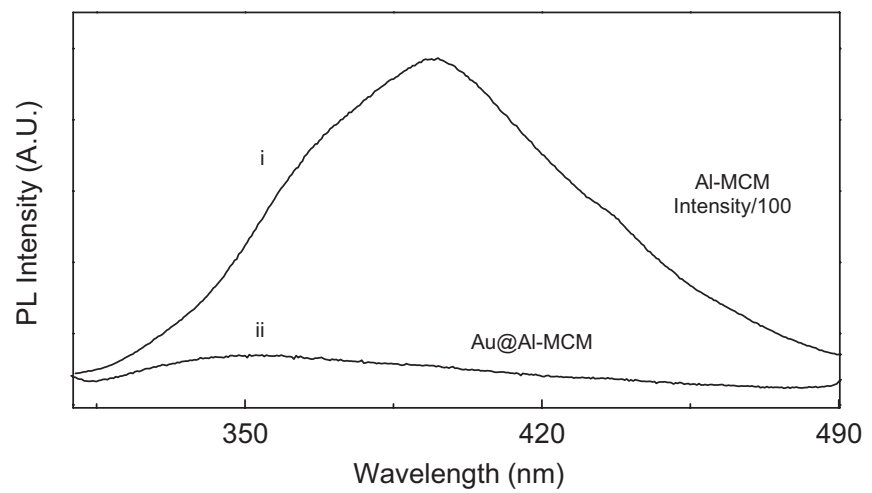

b

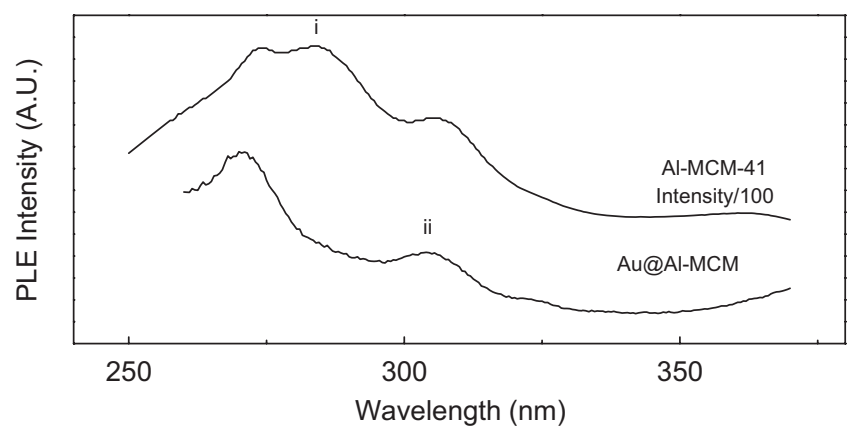

C

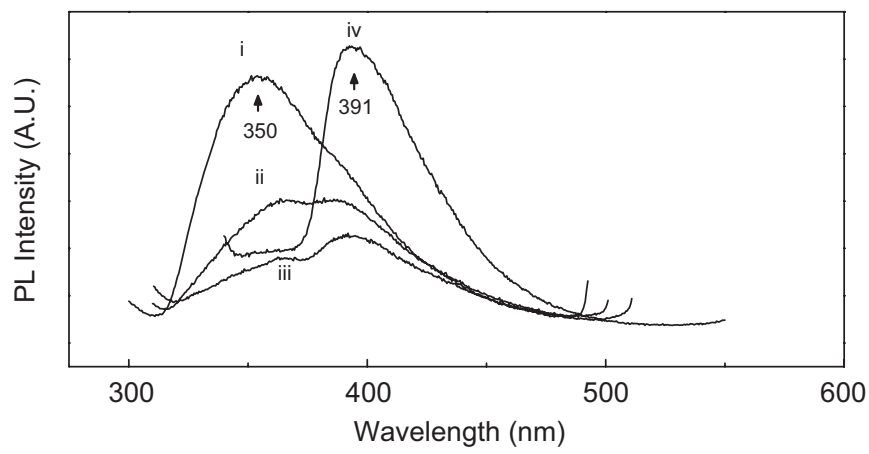

Fig. 6. (a) Photoluminescence spectra of (i) undoped Al-MCM-41 (ii) $\mathrm{Au} @ \mathrm{Al}-\mathrm{MCM}-41$, with excitation wavelength of $270 \mathrm{~nm}$. (b) Photoluminescence excitation spectra of (i) undoped Al-MCM-41 (ii) $\mathrm{Au} @ \mathrm{Al}-\mathrm{MCM}-41$, with monochromator fixed at $412 \mathrm{~nm}$. (c) Photoluminescence spectra of Au@MCM with different excitation wavelength. The curves of (i), (ii), (iii), and (iv) correspond to the excitation wavelength of $270,284,290$, and $306 \mathrm{~nm}$, respectively.
$\mathrm{Si}_{2}^{0}$ ) there are in the sample, the more $\mathrm{O}_{2}$ will be adsorbed to the sample by electrostatic forces. Meanwhile, the electrons trapped at the charged oxygen vacancy defects $\left(\mathrm{F}+\right.$ center and $\left.\mathrm{Si}_{2}^{0}\right)$ may be transferred to the adsorbed $\mathrm{O}_{2}$ to form the superoxide species $\mathrm{O}_{2}^{-}$. Therefore, one can infer that the PL of Al-MCM-41 at around $412 \mathrm{~nm}$ arises from the $\mathrm{F}+$ center, i.e. the oxygen vacancy trapping an electron with regards to the aluminum in the framework.

Let us now consider the effect of the incorporation of $\mathrm{Au}$ nanoparticles. Fig. 6(a) shows the PL spectra for Al-MCM-41 with and without $\mathrm{Au}$ nanoparticles, and the excitation wavelength was $270 \mathrm{~nm}$ for both cases. The peak with the larger intensity comes from the undoped Al-MCM-41, with the intensity divided by 100 . One can see that doping a small amount of $\mathrm{Au}$ results in a dramatic decrease in the PL intensity. It indicates that the excited electrons, rather than radiating through the radiative recombination centers of the defects, are instead easily dissipated as heat by the Au nanoparticles. Fig. 6(b) shows the PLE spectra with the monochromator fixed at $412 \mathrm{~nm}$. One can easily see that after doping with Au nanoparticles, the PLE peak at $284 \mathrm{~nm}$ originating from the defect $\mathrm{F}+$ centers disappears. This implies that there is a strong interaction between the Au nanoparticles and the charged defects. Therefore, the excited electrons return to the initial state nonradiatively through the Au nanoparticles and the PL intensity originally caused by the defects decays away. Indeed, very recently, it has been shown that the nucleation and growth of $\mathrm{Au}$ clusters is initially dominated by oxygen vacancy complexes [36]. We therefore suggest that there is a strong interaction between Au nanoparticles and structural charged oxygen vacancy defects in the support $(\mathrm{F}+$ center $)$, which can greatly reduce the PL intensity. Finally, we can see from the PL spectra of Au@Al-MCM-41 excited by different wavelengths that only the 350 and $391 \mathrm{~nm}$ peaks survive as shown in Fig. 6(c). This result provides additional evidence to support our claim that both emissions arise from the similar oxygen excess defects.

\section{Conclusion}

We have reported a detailed study of the photoluminescence (PL) properties of Al-MCM-41. Strong PL enhancement of two orders has been found after the incorporation of aluminum atoms. With the help of the PLE spectra, EPR spectra, and previous reports, we have identified the charged oxygen vacancies and excess defects as being responsible for the emission. This result implies that the incorporation of $\mathrm{Al}$ can greatly enhance the generation of oxygen related defects. We have also shown that when $\mathrm{Au}$ nanoparticles were deposited onto Al-MCM-41, the PL intensity decayed dramatically. It is found that the strong interaction between the Au nanoparticles and the charged oxygen defects is responsible for the reduction of the PL intensity after doping with $\mathrm{Au}$ nanoparticles. As a consequence, the interaction helps to stabilize $\mathrm{Au}$ nanoparticles and prevents them from sintering during the high 
temperature treatment. In addition, it enhances the transfer of the trapped electron in $\mathrm{F}+$ center to the absorbed $\mathrm{O}_{2}$ molecule, which leads to the formation of $\mathrm{O}_{2}^{-}$radical and the enhancement of $\mathrm{CO}$ oxidation. Our result therefore not only illustrates the interesting optical phenomena of Al-MCM-41, but also provides useful information for a better understanding of the enhanced catalytic activity in $\mathrm{Au} @ \mathrm{Al}-\mathrm{MCM}-41$.

\section{Acknowledgments}

This work was funded by the National Science Council and Ministry of Education of the Republic of China.

\section{References}

[1] R. Mokaya, W. Jones, J. Mater. Chem. 9 (1999) 555.

[2] M. Kwanten, B.A.M. Carrie're, P.J. Grobet, P.A. Jacobs, Chem. Commun. (2003) 1508.

[3] A. Palani, A. Pandurangan, J. Mol. Catal. A 226 (2005) 129.

[4] J.Y. Ying, C.P. Mehnert, M.S. Wong, Angew. Chem. Int. Ed. 38 (1999) 56.

[5] A. Sayari, Chem. Mater. 8 (1996) 1840.

[6] R. Neumann, A.M. Khenkin, Chem. Commun. (1996) 2643.

[7] C.T. Kresge, M.E. Leonowicz, W.J. Roth, J.C. Vartuli, J.S. Beck, Nature 359 (1992) 710.

[8] M. Haruta, Chem. Rec. 3 (2003) 75.

[9] G.C. Bond, D.T. Thompson, Catal. Rev. Sci. Eng. 41 (1999) 319.

[10] W.S. Epling, G.B. Hoflund, J.F. Weaver, S. Tsubota, M. Haruta, J. Phys. Chem. 100 (1996) 9929.

[11] H.P. Lin, C.Y. Mou, Acc. Chem. Res. 35 (2002) 927.

[12] Y.D. Glinka, S.H. Lin, L.P. Hwang, Y.T. Chen, J. Phys. Chem. B 104 (2000) 8652.

[13] Y. Zhang, F. Phillip, G.W. Meng, L.D. Zhang, C.H. Ye, J. Appl. Phys. 88 (2000) 2169.

[14] J.L. Shen, C.F. Cheng, Current opinion in solid state, Mater. Sci. 7 (2003) 427.
[15] J.L. Shen, Y.C. Lee, Y.L. Lui, P.W. Cheng, C.F. Cheng, J. Phys. Condens. Matter 15 (2003) L297.

[16] J.L. Shen, P.N. Chen, Y.C. Lee, C.F. Cheng, Solid State Commun. $122(2002) 65$.

[17] S. Dzwigaj, J.M. Krafft, M. Che, S. Lim, G.L. Haller, J. Phys. Chem. B 107 (2003) 3856.

[18] E. Gianotti, H. Yoshida, V. Dellarocca, L. Marchese, G. Martra, S. Coluccia, Res. Chem. Int. 29 (2003) 681.

[19] M.A. Stevens Kalceff, M.R. Phillips, Phys. Rev. B 52 (1995) 3122.

[20] H.J. Chang, Y.F. Chen, H.P. Lin, C.Y. Mou, Appl. Phys. Lett. 78 (2001) 3791.

[21] M.E. Gimon-Kinsel Jr., K.J. Balkus, K. Groothuis, Micropor. Mesopor. Mater. 20 (1998) 67.

[22] N.Y. He, C.W. Yuan, Z.H. Lu, C. Yang, L.S. Liao, S.L. Bao, Q.H. Xu, Supramolecular Sci. 5 (1998) 523.

[23] J.H. Liu, A.Q. Wang, Y.S. Chi, H.P. Lin, C.Y. Mou, J. Phy. Chem. B 109 (2005) 40.

[24] A.Q. Wang, J.H. Liu, S.D. Lin, T.S. Lin, C.Y. Mou, J. Catal. 233 (2006) 186.

[25] G.G. Qin, J. Lin, J.Q. Duan, G.Q. Yao, Appl. Phys. Lett. 69 (1996) 1689.

[26] T. Kanashima, M. Okuyama, Y. Hamakawa, Appl. Surf. Sci. 79/80 (1994) 321.

[27] H.R. Philipp, J. Phys. Chem. Solids 32 (1971) 1935.

[28] L.N. Skuja, A.N. Streletsky, A.B. Pakovich, Solid State Commun. 50 (1984) 1069.

[29] L. Skuja, J. Non-Cryst. Solids 149 (1992) 77.

[30] G. Pacchioni, G. Ierano, Non-Cryst. Solid 216 (1997) 1.

[31] X.S. Fang, C.H. Ye, X.X. Xu, T. Xie, Y.C. Wu, L.D. Zhang, J. Phys. Condens. Matter 16 (2004) 4157.

[32] Y. Du, W.L. Cai, C.M. Mo, J. Chen, L.D. Zhang, X.G. Zhu, Appl. Phys. Lett. 74 (1999) 2951.

[33] X.S. Peng, L.D. Zhang, G.W. Meng, X.F. Wang, Y.W. Wang, C.Z. Wang, G.S. Wu, J. Phys. Chem. B 106 (2002) 11163.

[34] X. Li, M.A. Vannice, J. Catal. 151 (1995) 87.

[35] P. Claus, A. Bruckner, C. Mohr, H. Hofmeister, J. Am. Chem. Soc. $122(2000) 11430$.

[36] B.K. Min, W.T. Wallace, A.K. Santra, D.W. Goodman, J. Phys. Chem. 108 (2004) 16339. 